For numbered affiliations, see end of the article.

\section{Correspondence to}

Dr Ganesh Acharya, Department of Clinical Science, Intervention and Technology (CLINTEC), Karolinska Institute and Centre for Fetal Medicine, Karolinska University Hospital, Stockholm SE-141 86, Sweden; ganesh. acharya@ki.se

Received 1 February 2018 Revised 5 February 2018 Accepted 15 February 2018

\section{S Linked}

- http://dx.doi.org/10.1136/ bmjsrh-2017-101866

Check for updates

To cite: Acharya $\mathrm{G}$, Liang $\mathrm{H}$. BMJ Sex Reprod Health 2018:44:134-135.

\title{
Abortion politics: do TRAP laws have an impact on women's health?
}

\section{Ganesh Acharya, ${ }^{1}$ Huan Liang ${ }^{1,2}$}

Abortion is regulated by law in most (if not all) countries, with a view to preventing abortion except under defined circumstances, and ensuring that abortions are performed safely. Abortion is allowed in 97\% of the United Nations' member states in order to save pregnant women's lives. ${ }^{1}$ Today abortions are increasingly provided by healthcare personnel other than doctors, in community settings or even at home rather than in hospitals, ${ }^{23}$ and have become very safe in most countries where they are legal and accessible. ${ }^{24}$ However, regulations vary significantly around the world. ${ }^{1}$

In considering what legal position should be advocated and how regulation affects women's health, it should be remembered that provision of safe abortion services was driven by the public health necessity to reduce maternal mortality, not as a primary human rights issue. The proportion of unsafe abortions is significantly higher in countries with highly restrictive abortion laws compared with those with liberal and less restrictive laws. ${ }^{4}$ Maternal mortality still remains unacceptably high in countries where abortion is illegal.

Even in some highly developed, democratic and affluent countries, such as the UK and the USA, complete decriminalisation of abortion has not been achieved yet, and policies that impose impractical, 
costly and resource-intensive requirements on abortion providers may have a negative impact on abortion accessibility and on women's health. However, reducing abortion numbers is also a worthwhile goal from the perspective of health policymakers, and of women themselves. How best to achieve that continues to dominate the political debate, especially in the USA.

Governments' priorities and policies have an impact on both health and healthcare ethics. Undoubtedly, educating girls and women and providing easy access to birth control is an effective way of reducing the need for an abortion. However, enforcing policies such as so called Targeted Regulation of Abortion Providers (TRAP) laws may have a negative impact on the accessibility of abortion services, and is unlikely to support women's health. Conversely, a government policy that encourages women to have an abortion to meet national family planning targets or a society that expects women to abort a female fetus cannot be considered humane or ethical even if the access to abortion services is excellent and procedures are medically safe.

The systematic review by Austin and Harper ${ }^{5}$ published in this issue of the journal aimed to evaluate the impact of TRAP laws on population-level abortion trends, gestational age at presentation, and measures of self-perceived burden. The authors conclude that certain TRAP laws may have an impact on state-level abortion rates and the experience of obtaining an abortion in the USA.

The study is limited by small numbers $(n=6)$ of included studies, and heterogeneity in design, methodology and reporting, preventing quantitative measurement of the impact of exposure to TRAP laws (composite or individual components) and meta-analysis. The resulting narrative synthesis inevitably carries the risk of desirability bias and limited generalisability. This systematic review does provide a welcome reminder that TRAP laws are not solely a US-specific phenomenon and their impact on abortion services needs to be investigated in other settings too. However, given abortion is already known to be safe in deregulated settings, the prior probability that extensive regulatory efforts will benefit women's health is very low. It may, rather, be a question of measuring the degree of detriment.

\section{Author affiliations}

'Division of Obstetrics and Gynecology, Department of Clinical Science Intervention and Technology, Karolinska Institutet and Center for Fetal Medicine, Karolinska University Hospital, Stockhom, Sweden

${ }^{2}$ Department of Obstetrics, Obstetrics and Gynecology Hospital of Fudan University, Shanghai, China

Funding This research received no specific grant from any funding agency in the public, commercial or not-for-profit sectors.

Competing interests None declared.

Patient consent Not required.

Provenance and peer review Commissioned; internally peer reviewed.

(C) Article author(s) (or their employer(s) unless otherwise stated in the text of the article) 2018. All rights reserved. No commercial use is permitted unless otherwise expressly granted.

\section{REFERENCES}

1 United Nations, Department of Economic and Social Affairs, Population Division. Abortion policies and reproductive health around the world. United Nations publication, 2014. Sales No. E.14.XIII.11. http://www.un.org/en/development/desa/populatio $\mathrm{n} /$ publications/pdf/policy/AbortionPoliciesReproductiveHealth. pdf (accessed 5 Feb 2018).

2 Barnard S, Kim C, Park MH, et al. Doctors or mid-level providers for abortion. Cochrane Database Syst Rev 2015;7:CD011242.

3 Rocca CH, Puri M, Shrestha P, et al. Effectiveness and safety of early medication abortion provided in pharmacies by auxiliary nurse-midwives: a non-inferiority study in Nepal. PLoS One 2018;13:e0191174.

4 Ganatra B, Gerdts C, Rossier C, et al. Global, regional, and subregional classification of abortions by safety, 201014: estimates from a Bayesian hierarchical model. Lancet 2017;390:2372-81.

5 Austin N, Harper S. Assessing the impact of TRAP laws on abortion and women's health in the USA: a systematic review. BMJ Sex Reprod Health 2018;44:129-34. 